\title{
Do patriarcalismo em Semente de Bruxa, de Margaret Atwood
}

\section{About the Patriarchalism in Hag Seed, by Margaret Atwood}

Gil Derlan Silva Almeida ${ }^{1}$

https://orcid.org/0000-0002-0270-5149

Sebastião Alves Teixeira Lopes ${ }^{2}$

https://orcid.org/0000-0001-6912-0105

\begin{abstract}
Resumo: Os estudos de linha feminista canadense ganharam força e notoriedade nos anos 90 com a contribuição da narrativa de Margaret Atwood. Considerada uma das maiores escritoras de língua inglesa da atualidade, suas obras retratam situações de assujeitamento de mulheres e a força com que o patriarcalismo domina e opera sobre o público feminino. Neste artigo, objetivamos analisar o patriarcalismo e suas implicações dentro da narrativa atwoodiana de Semente de Bruxa (2018). A obra é releitura de A Tempestade (2014) de William Shakespeare, onde se entrelaçam diversas questões e temas, dos quais o patriarcalismo se faz presente e reflete no enredo a situação de poderio de homens sobre personagens femininas, repreendendoas e silenciando-as. Como aporte teórico são usadas as discussões propostas por Barbosa (2014), Barreto (2004), Felman (1993), Pateman (1993) e Perrot (2017), afirmando assim como o patriarcalismo atuava na vida e comportamento das personagens que compunham o enredo de Semente de Bruxa (2018).
\end{abstract}

Palavras-chave: Margaret Atwood; Semente de Bruxa; Patriarcalismo.

\footnotetext{
${ }^{1}$ Mestrando em Letras/Literatura pela Universidade Federal do Piauí (UFPI). Especialista em Língua Inglesa pela Faculdade Latino-Americana em Educação (FLATED). Graduado em Letras/Língua Inglesa pela Universidade Estadual do Tocantins (UNITINS). Graduado em Letras/Língua Portuguesa pela Universidade Estadual do Maranhão (UEMA). Professor EBTT do Instituto Federal do Maranhão (IFMA), Campus Presidente Dutra. E-mail: gilderlansilva@hotmail.com

2 Pós-doutor. Doutor em Letras/Literaturas de Língua Inglesa pela Universidade de São Paulo (USP). Professor do Programa de Pós-graduação em Letras e do Departamento de Línguas Estrangeiras da Universidade Federal do Piauí (UFPI). E-mail: slopes10@uol.com.br
} 


\begin{abstract}
The canadian feminist studies gained force and notoriety in the 1990s with the contribution of Margaret Atwood's narrative. Considered one of the greatest writers of English language of the present time, her works describe situations of obliteration of women and the force with which patriarchalism dominates and operates on the feminine public. In this article, we aim to analyze patriarchalism and its implications in the atwoodian narrative Hag Seed (2018). Her work is a retelling of The Tempest (2014) by William Shakespeare, where various questions and themes are interlaced, patriarchalism presents and reflects in the plot the situation of men's power over female characters, scolding them and silencing them. As theoretical contribution are used the discussions proposed by Barbosa (2014), Barreto (2004), Felman (1993), Pateman (1993) and Perrot (2017). In this way, affirming how patriarchalism acted in the life and behavior of the characters that composed the plot of Hag Seed (2018).
\end{abstract}

Keywords: Margaret Atwood; Hag Seed; Patriarchalism.

\title{
INTRODUÇÃO
}

Durante séculos, a figura da mulher sempre ocupou um espaço de inferioridade e diminuição em relação ao homem. Considerada incapaz e frágil, restavam-lhes apenas as atividades inerentes ao lar: cozinhas, lavar, passar e cuidar da vida dos filhos. Os homens deveriam ocupar o centro da sociedade e da família, todo o poder e soberania estavam direcionados a estes. Assim formou-se um sistema falocêntrico de dominação que perdura até os dias de hoje.

Na literatura, esta dominação também se faz presente em inúmeros enredos e obras desde os cânones do passado até as produções contemporâneas. Enquanto ao protagonista, quase sempre um homem, cabe o papel de líder da casa, condutor do fio narrativo das ações, representante do poder e do respeito, à mulher é atribuído o papel de submissa e subordinada.

Analisam-se aqui os traços de patriarcalismo presentes na obra Semente de Bruxa (2018) da autora Margaret Atwood. São evidenciados estes comportamentos por parte do protagonista do enredo, o senhor Felix Philips, em relação às personagens Miranda, Anne Marie e Estelle. A primeira, sua filha, observada na trama em duas óticas: a primeira viva, e a segunda quando esta assume a posição de espírito ou presença que acompanha o protagonista no desenrolar das ações. Anne Marie, atriz e colega de trabalho de Felix e Estelle, senhora que auxilia secretamente o protagonista na sua trama e nutre por este algum sentimento.

As marcas da ordem patriarcal são demonstradas em discursos, mas acima de tudo, estas marcas se intensificam na ausência destes. Vozes silenciadas por um senhor que tem planos, que nega travessões a nossas personagens. Uma vez vistas pelo olhar alheio, bem como escutadas pela enunciação do outro. Deparamo-nos com um sistema que propicia a subalternidade, a inferiorização e força de um senhor sob suas mulheres. 


\section{AS MULHERES DE SEMENTE DE BRUXA E O PATRIARCALISMO DE FELIX}

Tendo sua primeira versão publicada em 2016, Semente de Bruxa, de Margaret Atwood é uma obra que discute questões profundas do âmago da existência humana. Perdão, remissão, mas também a própria vingança como elemento circundante e estruturador deste enredo. Atwood reescreveu Shakespeare, ou melhor o releu, e fez isso com o clássico A Tempestade. Enquanto a história shakespeariana nos brinda com as tramas de Próspero e seu plano de vingança contra seus inimigos que destruíram sua vida e lhe tomaram o ducado, Semente de Bruxa nos traz a história de Felix Phillips, o Próspero na versão atwoodiana. A autora canadense reescreve o enredo de Shakespeare e traz na narrativa artifícios para discutir temas que desde a época elisabetana ainda merecem relevância nas discussões. Conforme aponta Maria do Socorro Baptista Barbosa:

\footnotetext{
Em muitos outros romances da autora canadense também é possível perceber essa preocupação. É a autora de língua inglesa hoje que talvez mais discute as diversas facetas dessa realidade na qual vivemos, na qual não se pode mais pensar de forma maniqueísta e dicotômica, mas sempre de forma plural e mutável, como as próprias personagens atwoodianas. (BARBOSA, 2014, p. 104).
}

A história de Semente de Bruxa centra-se na vingança de Felix, um diretor de teatro que estava produzindo A Tempestade para o Festival de Makeshiweg, e que tem seu emprego, posto e posição usurpados por Thony, seu assistente pessoal e financeiro. Com a ajuda de políticos influentes que também eram desafetos do passado de Felix, Thony destrona nosso protagonista e provoca sua demissão da companhia. Para vingar-se, Phillips recolhe-se ao anonimato e vigia seus inimigos de longe. Quando convidado a ser professor de teatro de um curso de Leitura e Escrita para detentos em uma penitenciária, Felix vê a oportunidade de vingarse por meio da encenação de $A$ Tempestade, seu antigo projeto interrompido.

Em diálogo intertextual, percebemos que Atwood remontou o enredo de Shakespeare com uma primazia e fidelidade dignas do grande nome feminino da literatura canadense. Desta forma, Semente de Bruxa não é apenas uma obra da atualidade sobre um cânone da literatura mundial, é a própria reescritura do cânone, um jeito de ver Atwood, ao passo que se contempla 
Shakespeare em conjunto.

Estas análises literárias passaram-se a fazerem-se necessárias desde que a consideração dos elementos externos à obra, mostraram sua transfiguração dentro das narrativas. As diversas problemáticas de uma sociedade que consume estas produções tornaram-se eixo dos enredos e narrativas onde o leitor saindo da perspectiva passiva, agora conseguia se enxergar nas linhas que outrora apenas lia. Este leitor podia se enxergar em tais personagens, presenciando sua vida, costumes e comportamentos naquelas linhas. Dentro destas páginas o patriarcalismo que governava e subjugava a vida de inúmeras mulheres foi retratado por diversos nomes da literatura, onde no Canadá, esta voz se fez presente com Margaret Atwood ${ }^{3}$, principalmente.

O patriarcalismo e seus diversos desdobramentos apresentam-se na história e na literatura como fenômeno que acompanhou a humanidade e que sempre foi fator de controle do público masculino sobre o feminino. Desde a Antiguidade, estas posturas são responsáveis por inúmeras atrocidades e violências que fizeram alvo em muitas mulheres, ferindo-as não só fisicamente, mas também propiciando o cerceamento de seus direitos e liberdades em uma escala de violências de gênero que colocou o feminino em posição de inferioridade e rebaixamento nos diversos setores da sociedade. Para Barreto (2004):

[...] patriarcalismo é uma estrutura sobre as quais se assentam as sociedades contemporâneas. Segundo ela, uma sociedade patriarcal é caracterizada "por uma autoridade imposta institucionalmente, do homem sobre mulheres e filhos no ambiente familiar, permeando toda organização da sociedade, da produção e do consumo, da política, à legislação e à cultura". (BARRETO, 2004, p. 64).

Verificamos assim, que o patriarcalismo se pauta no poderio de um ou vários homens sobre mulheres, centrando-se na ideia de que o público masculino tem sua superioridade institucionalizada e inquestionável, e no tocante a mulher só resta o papel de submissa, passiva, ou seja, alguém que deve obediência ao seu senhor de forma incondicional.

A principal personagem feminina de A Tempestade (2018) de William Shakespeare ganha uma nova oportunidade de fazer-se presente por meio da escrita atwoodiana. Miranda é

\footnotetext{
${ }^{3}$ Segundo Barbosa (2014, p. 96): "Escrita em 1965 e publicada em 1969, a narrativa de Atwood surge pouco antes daquilo que as críticas feministas chamam de 'segunda onda feminista'. A própria autora chama seu texto de 'protofeminismo', embora tal termo seja controverso, já que indicaria a inexistência do termo 'feminismo'. Entretanto, não se pode negar que o romance de Atwood quebra uma série de tabus que se tornam importantes para essa 'segunda onda' do 'feminismo canadense'.
} 
filha de Próspero na primeira obra, mas em Semente de Bruxa (2018), da canadense Margaret Atwood, esta reaparece em conjunto a Felix, a versão do pai controlador para o nosso romance canadense. A narrativa nos apresenta um pai controlador que por meio do discurso de proteção da família priva a personagem de liberdade e a faz enclausurada na sua teia de artimanhas, onde o poder está sempre em suas mãos, colocando assim a personagem sempre abaixo.

Este comportamento exprime fielmente a ideia de pai patriarcal que se dá na sociedade. Felix, protagonista de Semente de Bruxa, é um diretor de teatro, como também é um homem amargurado que busca vingança contra aqueles que no passado destruíram sua vida e o jogaram no fundo do poço do ódio e da reclusão. Sua única companhia é a filha Miranda que morre logo nos primeiros momentos da história vítima de uma meningite fatal. Por sua vez, Feliz, culpa-se incansavelmente, pois atribui esta tragédia à ausência em sua função de pai responsável, uma vez que estava extremamente imerso em seu trabalho de produção do espetáculo de $A$ Tempestade para o teatro.

\footnotetext{
Febre Alta. Meningite. Tentaram avisá-lo. As mulheres. Mas ele estava em um ensaio, com ordens restritas para não ser interrompido. E elas não souberam o que fazer. Quando finalmente chegou em casa, houve lágrimas de desespero e o percurso de casa até o hospital, mas era tarde demais, tarde demais. (ATWOOD, 2018, p. 24).
}

Ao ler estas palavras parece que estamos lidando com um pai amoroso e que não dialoga com a figura e descrição de patriarcalismo acima apresentados por nossas palavras. No entanto, no decorrer do enredo, a narrativa atwoodiana revela-nos um Felix que assim como o original Próspero shakespeariano, usa-se do pretexto de cuidador da família e chefe desta organização nuclear para conseguir o que quer. Será no silenciamento e apagamento da personagem feminina Miranda, bem como algumas outras que este priorizará seus desejos e anseios pessoais sob qualquer coisa.

Conhecemos assim, nossa personagem sem voz, sempre representada sobre a de seu pai patriarcal Felix. Miranda que morreu no início da narrativa, se faz presente em toda a história como um fantasma, uma presença que acompanha seu pai, um ser que não habita mais esse plano fisicamente, mas continua ali sendo companhia de seu senhor enquanto for necessário a este. Esta menção a personagem representada sob a voz e pensamentos de seu senhor feliz, remonta dentro da ótica patriarcalista a própria noção de mulheres como seres sem autonomia que só se faziam na presença de um homem. Tal visão falocêntrica perdurou a história das 
mulheres por um longo período. Como afirma Michelle Perrot: "As mulheres não representavam a si mesmas, escreve ele. "Elas eram representadas. [...] Ainda hoje, é um olhar de homem que se lança sobre a mulher" e se esforça para reduzi-la ou seduzi-la". (PERROT, 2017, p. 24).

Esta representação sempre consagrou o homem como centro do pensamento epistemológico e social. A mulher enquanto sua companheira, era tida como um ser acessório, se detendo a quando fosse necessária. Esta postura patriarcal, pautou-se na ideia de que o homem era o responsável nato pela vida da própria mulher, ou seja, as mulheres precisavam estar silenciadas, sua falta de voz seria a certeza da manutenção do poderio masculino (FELMAN, 1993). O detentor da voz feminina seria seu pai, marido, filho, namorado, entre outros homens que habitassem esse universo, mas acima de tudo a falta de voz seria claramente a certeza de que os rastros de sua presença não fossem deixados.

A ideia de tornar-se pai e continuar sua linhagem já desde os tempos remotos contribuiu para a perpetuação de uma visão patriarcal. Na literatura não eram grandes os números de protagonistas que tinham filhos. É somente a partir de 1950 e 1960 que dentro do bojo da literatura as narrativas passaram a mudar esse quantitativo aumentando-o. $\mathrm{O}$ protagonista agora com filhos passava a ser a representação de um herói ${ }^{4}$. Era como se a constituição de sua prole desencadeasse um processo de humanização, ou seja, não haveria mais defeitos para esta figura masculina. (BORNEO FUNCK, 2016)

Com a morte de Miranda e a derrocada da perda de seu emprego e posição em consequência do golpe de seus inimigos, nosso personagem começa a esquematizar sua vingança. É interessante apontar que Felix acredita que com a produção de A Tempestade conseguiria por um fim ao seu sofrimento de pai enlutado, ou seja, a própria encenação na peça de uma Miranda, que há tempos deveria ter acontecido, seria a liberdade para a alma de sua Miranda morta pela doença. Notamos aí novamente a representação vindo do Outro para a personagem sem voz e poder. Mas além disto, não seria o próprio interesse pessoal em concluir seu projeto a grande motivação de Felix? O que seria o mais importante como motor desse projeto? A liberdade e paz para o espírito da filha ou a vingança contra seus inimigos?

Vemos na verdade que a redenção da alma da filha não passa de uma desculpa patriarcal para a busca da concretização dos próprios anseios pessoais de nosso protagonista.

\footnotetext{
${ }^{4}$ No artigo Narrativa, Alteridade e Gênero, de Paulo Sérgio Marques (UNESP- Araraquara), é discutido sobre o trajeto masculino do herói. Como este personagem, o âmbito literário tem sua personalização arraigada cada vez mais em estruturas patriarcais, a partir da nomeação de pai. O autor fala que ao sujeito masculino será concedida a noção de herói, com poder de conquista e vitória. É a experiência patriarcal que demarca a apropriação da vitória sobre o outro. (MARQUES, 2007).
} 
O foco de Felix é sua vingança e não a paz a ser alcançada pelo espírito de Miranda que o acompanha no decorrer da narrativa, mais uma vez a desculpa do bem familiar remonta e maqueia o interesse patriarcal envolto.

No clássico original A Tempestade (2018) de William Shakespeare nos deparamos com um Próspero que usa de sua posição de mago, pai e homem para controlar e usar como bem Ihe interessa a vida de sua filha Miranda. Com o desejo mais que potente de recuperar seu ducado e conseguir sua sonhada vingança contra o irmão usurpador, este personagem molda os fatos e o desenrolar das ações como alternativa para conquistar a realização de suas vontades e planos.

Seja no apagamento de sua esposa, que sequer recebe um nome na peça de Shakespeare, ou pela descrição feita sobre a bruxa Sycorax, Próspero cria imagens de mulheres que são representam sob a sua ótica, fazendo com que a história se molde nos parâmetros de sua mente, opinião e magia. Quando nos referimos a jovem Miranda de A Tempestade, a carga de patriarcalismo é mais do que intensificada, afinal desde o sono de sua filha que é controlado, como também as ações pré-determinadas pelo pai, Miranda é uma personagem totalmente submissa numa relação de exploração.

\begin{abstract}
Essas linhas retratam um caráter coletivo e autoconfiante que não é afetado por condições externas - um "pai" forte e estável que ainda diz à filha que tudo o que foi feito foi feito para seu benefício. Essas linhas introduzem as estruturas e os estereótipos comuns que fundamentam uma sociedade patriarcal - um pai forte e emocionalmente estável que tem a responsabilidade de proteger seus filhos, especialmente as filhas. Os leitores que estão familiarizados com essa estrutura identificam-se imediatamente com Prospero. Essa revelação dá uma lacuna para o personagem que ele utiliza para justificar suas decisões. (SUJITHA, 2016, p. 394 tradução nossa). ${ }^{5}$
\end{abstract}

Segundo Sujitha (2016), Miranda não passa de um recurso de valor para Próspero, pois seu estabelecimento matrimonial com Ferdinando, seu futuro marido, seria a certeza de um futuro promissor para si próprio, um estratagema político, que ao passo que consagraria seu retorno paro o título de duque de Milão, selaria as alianças políticas necessárias com Nápoles

\footnotetext{
${ }^{5}$ Conforme original que segue: These lines portray a collected and self- assured character who is not affected by external conditions- a strong and stable 'father' who further tells his daughter that whatever was done, was done for her benefit. These lines introduce the common structures and stereotypes that underlie a patriarchal society- a strong and emotionally stable father who has the responsibility to protect his children especially the daughters. The readers who are familiar with this structure immediately identify with Prospero. This revelation gives a gap for the character which he utilizes to justify his decisions. (SUJITHA, 2016, p. 394)
} 
para os períodos vindouros.

Outrossim, no texto de Atwood, Felix que tem a companhia de sua Miranda imaginária não dá sequer voz direta a esta personagem, este direito ao menos no texto shakespeariano se faz presente, os comportamentos são cerceados e Próspero controla sua filha como um mestre o faz com um marionete, no entanto vemos as falas de Miranda. Todas as falas da Miranda atwoodiana são sempre enunciadas em um discurso indireto vindo de Próspero. Nossa personagem além de morta e representada sob outros olhos, não conquistou a autonomia sequer do uso de seus próprios travessões, tendo de se conformar com o dito sempre pelas palavras do Outro. Conforme apresentado na obra: “O que é cada coisa? Ela quer saber. De onde vieram e para que servem? A touca de natação? Os óculos de esqui? O que é natação, ou o que é esqui? Evidente que aqueles itens Ihes são desconhecidos: ela sabe tão pouco sobre o mundo exterior". (ATWOOD, 2018, p. 193).

Neste excerto, vemos que a presença de Miranda se faz junto a Felix, mas que esta não tem direito a suas falas, pois como se mencionou seus discursos são sempre levados e apresentados de forma indireta por Felix, a menina não tem poder de se expressar e a gama de informações as quais o leitor de Semente de Bruxa tem acesso são sempre ditas pelo pai. Essa silenciamento de Miranda seria uma forma de garantir que esta sempre estivesse abaixo do pai, não podendo gerar qualquer desconforto ou discordância a seu senhor. Tais colocações exemplificam Miranda sendo posta numa condição de subalternidade. Ao falarmos sobre subalternidade ratifica-se a ideia de que o Outro Miranda não tem sua própria voz e é sempre ouvida pela voz de alguém, nesse caso Felix.

O subalterno não é quem fala, mas sempre quem é ouvido pela voz do outro (SPIVAK, 2018). Questionamo-nos se realmente Felix tem essa procuração para falar por Miranda. Percebemos que na relação Felix- Miranda, o sujeito Felix tem poder sobre sua subordinada. Felix é sujeito e Miranda um Outro que só existe enquanto eco da voz de Felix. Não é por estar morta ou ser um espírito, mas porque esse espírito que poderia ter uma voz não lhe tem esse direito concedido.

Na própria obra A Tempestade, vemos que Próspero coloca Miranda em posição de subalternidade, sob um regime de vida patriarcal. Ela é seu objeto e ele seu senhor, como se fosse uma mercadoria nas mãos de um dono mercador. Esta afirmação se coaduna com a negociata de casamento entre Miranda e Ferdinando que se apaixonam, dois herdeiros de trono. Para quê algo mais promissor e conveniente? 
Para que qualquer estrutura seja criada e sustentada, é necessário ter um "outro" do outro lado. Para Prospero se tornar o governante, outros personagens, incluindo sua filha, precisam ocupar sua posição de objeto / sujeito (de uma escala). [...] Ela é uma posse valiosa para Próspero. Ele a treina de uma maneira que o beneficie. Ele decide o que ela deveria saber quando ela deveria saber e o que ela não deveria saber. Então, finalmente, suas decisões se tornam suas decisões. Sua ingenuidade se torna evidente quando ela diz a Próspero que para saber mais sobre seu passado nunca procurou "se intrometer" com seus próprios pensamentos. (SUJITHA, 2016, p. 398, tradução nossa). ${ }^{6}$

É notório também destacar que Felix coloca Miranda como seu Ariel na trama de Atwood, ou seja, o escravo de Próspero em A Tempestade de Shakespeare agora é simbolicamente atribuído em alguns momentos a Miranda. Mesmo que na narrativa e na peça a ser encenada na cadeia de Fletcher esse papel pertença ao detento $8 \mathrm{Handz}$, gênio da informática e que auxilia Felix fielmente na preparação e execução de todo o plano, é perceptível que Felix considera Miranda seu Ariel também. Assim como no teatro shakespeariano, o espírito que lhe ajuda é invisível na figura de Ariel, nossa garotinha stá nesse patamar simbólico de serva invisível. Esta posição só coloca nossa personagem no reforço dos níveis de servidão, agora não mais filha, mas serva. Este é o único momento que se percebe uma fala de Miranda, ou melhor de Ariel. Conforme vemos:

\footnotetext{
Aproxime-se, meu Ariel! - Ele se inclina para trás, como se estivesse ouvindo. - "Venha!"

Bem perto de seus ouvidos ele escuta a voz de Miranda. É apenas um sussurro, mas ele a escuta.

Salve, grande mestre, grave o senhor, salve! Venho dar a resposta que melhor o satisfaz, seja voar, nadar no fogo, flutuar nas nuvens aneladas, está sob a tua ordem resoluta Ariel e toda sua existência. (ATWOOD, 2018, p. 207).
}

Outro ponto na ótica de patriarcalismo que merece destaque são os posicionamentos

\footnotetext{
${ }^{6}$ Conforme o original que segue: For any structure to be created and sustained, it is necessary to have an 'other' on the other side. For Prospero to become the ruler, other characters including his daughter need to occupy their object/ subject (of a ruler) position. [...] She is a valuable possession for Prospero. He trains her in a manner that benefits him. He decides what she should know, when she should know it and what she shouldn't know. So ultimately it his decisions that become her decisions. Her naiveness becomes evident when she tells Prospero that to know more about her past never "meddle" with her thoughts. (SUJITHA, 2016, p. 398)
} 
de Felix com Anne- Marie. Esta jovem atriz é convidada por Felix para encenar Miranda na peça da penitenciária, pois era a atriz cotada e mais preparada para o papel nos tempos gloriosos do sr. Philips. Anne se apresenta na história como uma mulher forte, bem resolvida e que não precisa da proteção de ninguém. Num esboço de lançar sua postura patriarcal sob a personagem, ainda que sutilmente vemos a crítica da personagem aparecer sob Feliz. Nas palavras de Atwood:

- Você acha que vou me apaixonar por ele, certo? - diz Anne Marie. Você acha que eu sou tão fácil assim? - Ela cerra os dentes.

- Não, não. - diz Felix. - Deus a livre. Mas você vai precisar manter o bom senso quando estiver na personagem. Mesmo com a sua armadura tão forte.

- Você já está no personagem- diz Anne Marie, rindo. - Interpretando meu pai superprotetor. (ATWOOD, 2018, p. 165).

Nessa cena, Felix coloca Anne Marie como a menina frágil e delicada que precisa de seus cuidados. Quando questionada sobre se apaixonar ou não sobre o ator que interpretaria seu par romântico na peça, ela esclarece a Felix que ele já está sendo superprotetor. É como se essa postura fosse natural ao seu comportamento.

A intertextualidade no enredo de Semente de Bruxa é muito presente. Conseguimos perceber claramente a conversa entre as duas obras, onde essas vozes se misturam, o que dá um caráter mais intenso ao texto de Atwood. Felix sempre procura conseguir o que quer custe o que custar. Nas conversas com Anne Marie, este impõe sua posição e não aceita facilmente as colocações da colega de teatro. Esse ponto se intensifica a um grau que o personagem não consegue definir quem é o Felix real e quem é Próspero. As mesmas características, o mesmo comportamento dominador e patriarcal se misturam nos dois personagens em um só, ou seja, para nossa interpretação essa ação só confirma as posturas já esperadas para Felix, não é a capa do teatro e a vestimenta do personagem, é a personalidade sendo revelada.

Este excerto e cena se misturam com o texto shakespeariano, uma vez que o próprio Felix na narrativa se depara refletindo sobre a condição da Miranda original. Este vê a situação com os olhos que a personagem talvez usasse para ver Próspero, ou seja, nosso diretor de teatro estava conseguindo enxergar o que a jovem da ilha distante recebia de seu pai controlador. Do modo que vemos em Semente de Bruxa: 
[...] Pode ser por medo. Por uma fração de segundos, ele vê Próspero pelo olhar de Miranda, uma Miranda petrificada que percebeu subitamente que seu adorado pai é um completo maníaco, e ainda por cima paranoico. [...] A garota, coitada, está presa no meio do oceano com um bandido saturado de testosterona que quer estuprá-la e com um pai ancião que perdeu totalmente a cabeça. (ATWOOD, 2018, p. 167).

Este posicionamento na obra coaduna com a ideia de Pateman (1993) que coloca que o patriarcalismo surgiu inicialmente e se concentrou como base nos seios familiares, onde a figura do pai representava o auge dessa noção e uma forma de poderio inquestionável. É na figura do pai que essa noção se demonstra claramente. Um senhor que se intitula dono da estrutura familiar, uma rocha sólida que é responsável por toda a base do seu familiar. Suas ações são sempre respaldadas no bem-estar dos outros membros que compõem este círculo.

Outro ponto a se destacar sobre o patriarcalismo em Semente de Bruxa é a presença de outra personagem feminina que está sob as vontades e desejos do nosso protagonista Felix. No enredo, Felix conta com a ajuda de diversos personagens: seus vários alunos detentos, que não são poucos. Contudo é talvez dentre a gama de colaboradores para o plano de Felix, Estelle, o sua verdadeira súdita fiel e indispensável. Esta personagem aparece como o primeiro sinal que introduz Feliz ao mundo da penitenciária Fletcher. Com uma queda amorosa por nosso protagonista, esta mulher auxilia-o em todos os seus planos e necessidades. Desde burlar a segurança da penitenciária para que objetos incomuns estejam disponíveis para parte de sua vingança, até ajudar no estratagema final colocando suas vítimas na exata posição necessária, Estelle ocupa sempre a posição de serva de Felix. Parece-nos que este tem mais de um Ariel dentro deste universo, não só Miranda, mais também 8Handz e por fim Estelle.

O poder e comportamento patriarcal exercido por Felix sob Estelle se diferencia daquele lançado sob Miranda e Anne Marie na seguinte perspectiva: enquanto estas figuravam a representação de filha nos moldes patriarcais, esta remonta a ideia de esposa, ou seja, Felix tem a esposa com a servidão necessária para seus desejos e vontades. Estelle não se via nessa posição, estava submissa, mas em sua cabeça era uma boa oportunidade de ajudar Felix no que precisasse. Acreditava nas boas intenções do professor de teatro e cumpria seus mandos graciosamente. Conforma afirma Bourdieu: "[...] do mesmo modo a submissão feminina parece encontrar sua tradução natural no fato de se inclinar, abaixar-se, curvar-se, de se submeter ('o contrário de pôr-se acima de'), nas posturas curvas, na docilidade correlativa de que se julga convir à mulher". (2017, p. 38). 
Assim, percebemos a relação de submissão de Estelle junto a Felix, e este se usando disto para conseguir consolidar seus desejos pessoais de vingança. Na própria descrição, Estelle se define como um acessório que auxilie no desenrolar dos planos de Felix. Tal qual vemos na obra: "- Pense em mim como graxa - ela dissera. - Vou fazer as coisas correrem com suavidade, garanto". (ATWOOD, 2018, p. 236).

Para Perrot (2017) esta imagem são formas abusivas de tirania, uma vez que impõem conformismo. São quase como estigmas que a mulher carrega nessa relação de dominação masculina.

Podemos nos perguntar sobre a maneira pela qual as mulheres viam e viviam suas imagens, se as aceitavam ou as recusavam, se se aproveitavam delas ou as amaldiçoavam, se as subvertiam ou eram submissas. Para elas, a imagem é, antes de mais nada, uma tirania, porque as põe em confronto com um ideal físico ou de indumentária ao qual devem se conformar. (PERROT, 2017. p. 25).

Voltando a Miranda, nossa filha fantasma, temos um último momento desta personagem. Assim como no original shakespeariano, após o cumprimento da missão de vingança, Próspero liberta Ariel, este finalmente está com a tão sonhada liberdade após anos de prisão na madeira e posterior servidão ao seu senhor. Em Semente de Bruxa, é como se a paz que a alma de Miranda tanto necessita só pudesse ser concedida com o cumprimento da missão de Felix, pois esta paz só seria proporcionada pelo personagem. Este tinha as chaves da liberdade da sua alma, e não as soltaria até que sua vingança fosse concretizada. Somente ao fim da aventura vingativa é que este pai iria libertar sua filha, tal qual em analogia comparamos ao Próspero e Ariel da peça inglesa Agora que a presença de Miranda não era mais elemento fundamental para a saciar a solidão de Felix e seu inconformismo, pois este estava satisfeito com o plano bem executado, a alma pode ser livre e por fim encontrar paz. Sua função foi cumprida, sua presença não é mais necessária.

O que ele estava pensando, mantendo-a presa a ele todo esse tempo? Forçando-a fazer tudo o que ele pedia? Como ele havia sido egoísta! Sim, ele a ama: sua querida, sua única filha. Mas ele sabe o que ela realmente quer, e o que ele deve a ela.

- Seja livre para unir-se aos elementos- diz a ela. E, finalmente, ela é. (ATWOOD, 2018, p. 323). 
Felix sentia a necessidade agora de fazer Miranda livre, isso porque esta era a paga pelos serviços prestados. Assim como Ariel do original de Shakespeare, uma vez que o serviço fosse cumprido o senhor poderia conceder a liberdade a seu escravo. Este finalmente teria sua independência, não mais servindo a quem o escravizava. Ariel e Miranda ganharam a liberdade. Suas dívidas estavam quites, seu senhor estava satisfeito.

\section{CONSIDERAÇÕES FINAIS}

A presença do patriarcado e suas diversas manifestações aparecem nos textos literários como retrato do que muitas mulheres viviam e vivem em sua realidade. O engendramento social não está ainda livre destas posturas e práticas ainda. Na narrativa de Semente de Bruxa (2018) de Margaret Atwood percebemos uma relação clara de um personagem patriarcalista em uma relação de dominação e proveito as mulheres que permeiam o tecido literário analisado. Ao colocar estas posturas a bruxa canadense Atwood, como fora citada por alguns críticos de sua produção por inserir em suas literaturas visões distópicas, questiona como esse mesmo patriarcalismo de séculos atrás ainda se faz presente em uma sociedade dita tão moderna, ou para alguns até pós-moderna.

Nota-se que as personagens femininas integrantes do enredo passam por processos de submissão ao patriarcalismo imposto pelo protagonista. Tendo em vista o que foi apresentado, pode-se concluir que o pai patriarcal Felix sobrepõe seus desejos, vontades e anseios para acima das personagens com quem se relaciona, a desculpa do bem-estar da família e a felicidade são o véu que esconde a face egoísta e egocêntrica.

Ao reconhecermos a necessidade de dominação de nosso personagem Felix sobre Anne Marie, Estelle, mas sobretudo sobre Miranda vemos que a literatura shakespeariana não foi só relida e recontada numa roupagem mais atual, mas também que Felix e Próspero representem os mesmos tipos de homens, pais e companheiros que só tem de diferenciação o espaço e tempo em suas diferentes literaturas, mas tão iguais histórias de narrativa. O patriarcado de agora talvez esteja maquiado de uma nova roupagem mais atual, mais sofisticada. Não há mais a necessidade de escancaramento, mas ainda é problemática constante a ser discutida e analisada no âmbito literário e nos demais estudos, precisando assim sempre de atualização, pesquisa e atenção por parte da academia. 


\section{Referências}

ATWOOD, Margaret. Semente de Bruxa. Trad. Heci Regina Candiani. São Paulo: Morro Branco, 2018.

BARBOSA, Maria do Socorro Baptista. Feminismo em Atwood. In: MENDES, Algemira de Macêdo CARVALHO, Diógenes Buenos Aires de (org.). Literatura e gênero: relações de poder e representações literárias. Teresina: EDUFPI, 2014. p. 95-104.

BARRETO, Maria do Perpétuo Socorro Leite. Patriarcalismo e o Feminismo: uma retrospectiva histórica. Revista Àrtemis, v. 18, n. 1, p. 64-73, 2004.

BOURDIEU, Pierre. A dominação masculina. Trad. Maria Helena Kühner. 14. ed. Rio de Janeiro: Bertrand Brasil, 2017.

FELMAN, Shoshana. What Does a Woman Want?: reading and sexual difference. London: The John Hopkins University Press, 1993.

FUNCK, Susana Borneo. Crítica Literária Feminista: uma trajetória. Florianópolis: Insular, 2016. Série Estudos Culturais.

MARQUES, Paulo Sérgio. Narrativa, alteridade e gênero: o imaginário patriarcal e os arquétipos literários. Terra roxa e outras terras: Revista de Estudos Literários, v. 11. p. 61-76, 2007.

PERROT, Michelle. Minha História das Mulheres. Trad. Angela M. S. Côrrea. 2. ed. São Paulo: Contexto, 2017.

SHAKESPEARE, William. A tempestade $=$ The Tempest. Trad. Rafael Raffaelli. Florianópolis: Editora da UFSC, 2014. (Edição bilíngue).

SPIVAK, Gayatri Chakravorty. Pode o Subalterno Falar?. Trad. Sandra Regina Goulart Almeida, Marcos Pereira Feitosa, André Pereira Feitosa. Belo Horizonte: Editora UFMG, 2010.

SUJITHA, V. S. Politics of Absence: The Conflicting Positions and Gender Hierarchy in The Tempest. International Journal of English Language, Literature and Humanities, v. IV, n. VI, p. 393-406, jun. 2016. 